\title{
Effects of flow-habitat on body size and reproductive patterns in the sea anemone Metridium senile in the Gullmarsfjord, Sweden
}

\author{
Kenneth R. N. Anthony, Ib Svane \\ The Royal Swedish Academy of Sciences, Kristineberg Marine Research Station, Kristineberg 2130, S-450 34 Fiskebäckskil, \\ Sweden
}

\begin{abstract}
In the Gullmarsfiord, on the west coast of Sweden, a variety of morphs of Metridium senile (L.) are found. A small form (pedal disc diameter $0.3 \mathrm{~cm}$ ) is found in dense clones $(90 \%$ coverage) in high-flow habitats at 2 to $5 \mathrm{~m}$ depth, and larger forms (pedal disc diameter $=2.5$ to $3.5 \mathrm{~cm}$ ) are found abundantly in subtidal low-flow habitats where body size increases with depth. In order to investigate the adaptive significance of body size and laceration in $M$ senile from different current regimes, individuals of a large and small morph were reciprocally transplanted between a low-flow $\left(<5 \mathrm{~cm} \mathrm{~s}^{-1}\right)$ and a high-flow (>65 $\mathrm{cm} \mathrm{s}^{-1}$ ) subtidal habitat, and incidents of pedal laceration were monitored from August 1992 to January 1993. For comparison, 2 experiments (analogous to the field transplants) were carried out in laboratory flumes. The relative importance of sexual reproduction in the 2 habitats was investigated by comparing gonad sizes of mature females. The results of field and laboratory experiments showed that individuals from the high-flow habitat decreased their rate of laceration in low flow, but maintained a higher rate of pedal laceration than the low-flow population irrespective of site of transplantation, suggesting that properties of asexual proliferation possess both habitat-related and intrinsic components. Sexual reproductive allocation was positively correlated with body size and was significantly greater among females from the low-flow population. When adjusted for a common body weight, however, differences in gonad sizes were insignificant. Frequent asexual replication of the genet and fertility at a small size $(1 \mathrm{~g})$ are argued to be important features in the high-flow habitat which compensate for the reduced reproductive output of individual anemones and eventually maximize clonal fitness.
\end{abstract}

KEY WORDS: Sea anemone Metridium senile Flow - Body size - Pedal laceration - Reproduction

\section{INTRODUCTION}

The sea anemone Metridium senile (L.) is a conspicuous and quantitatively dominant species in hard bottom assemblages in the Gullmarsfjord on the west coast of Sweden. It is particularly abundant at depths from 0 to $15 \mathrm{~m}$ but may be found in dense patches or clones in deeper waters. $M$. senile occurs in populations with different size-frequency distributions and colour variations. Small, red-brown individuals occur at shallow sites in the fjord and dominate at certain sites where the current velocity periodically reaches $100 \mathrm{~cm} \mathrm{~s}^{-1}$. Larger individuals are commonly found in sheltered localities in the Gullmarsfjord proper, predominantly below $15 \mathrm{~m}$ depth, or at deeper sites in the archipelago at the mouth of the fjord. The large form includes several colour morphs, whereas the small form is mainly monomorphic, indicating differences in clonal diversity (Hoffmann 1976, 1986, Purcell 1977).

A similar size-distribution pattern has been described for Metridium senile in the British Isles and along the west and east coasts of North America, and attempts have been made to divide morphs into new species or subspecies (Stephenson 1935, Fautin et al. 1989). In the British Isles, 2 varieties of $M$. senile, distinguished by size, degree of lobing of the oral disc and shape while contracted, were recognized by Stephenson (1935). According to Bucklin (1985), the large morph (M. senile var. dianthus) is found in shallow water while the small morph ( $M$. senile var. pallidum) is typically infralittoral and is only occasionally found sublittorally. Bucklin (1985) found no genetic evidence, 
however, permitting a systematic division of $M$. senile, but concluded that the varieties in the British populations were ecophenotypes or morphological forms determined by habitat conditions.

As for numerous other species of sea anemone, Metridium senile reproduces both sexually and asexually (Chia 1976). Sexual reproduction occurs annually by shedding eggs and sperm into the water which results in free-swimming planulae (Gemmill 1920), while asexual reproduction occurs regularly by fragmentation of the pedal disc, a process known as pedal laceration (Hammatt 1906, Chia 1976).

Several authors have noted the relationship between flow velocity and clonal proliferation by pedal laceration in populations of Metridium senile on the east coast (Shick et al. 1979, Shick \& Hoffmann 1980) and the west coast (Bucklin 1987) of North America. Two general hypotheses have been proposed: populations of $M$. senile are structured either through differential indeterminate growth and rate of laceration in response to flow (Shick \& Hoffmann 1980, Bucklin 1987), or through selection of well-adapted genotypes (Hoffmann 1986). Shick et al. (1979) and Shick \& Hoffmann (1980) suggested that different size-frequency distributions is an accommodation to morphological constraints brought about by differential food availability associated with the position of the tentacle crown within the boundary layer (Koehl 1977. Shick et al. 1979), and furthermore proposed that genotype is a determinant of success in a given flow environment. When comparing populations of small intertidal $M$. senile with harbor float populations of large anemones, Bucklin (1987) supported the hypothesis that size-frequency distributions of $M$. senile reflect different physical constraints and food availability in different flow regimes, as well as adaptive responses to these habitat conditions. In his review, Shick (1991) provides a model considering both the mechanical and nutritional effects of current speed on body size and clonal growth in $M$. senile.

According to Bucklin (1987), gonad size is positively correlated with body size in Metridium senile. If flowhabitat affects the size-frequency distribution and population structure of $M$. senile, either by stimulating pedal laceration or by favouring well-adapted genotypes with high intrinsic rates of laceration, it may influence both the sexual and asexual components of genet fitness. The purpose of this study is to compare the patterns of clonal growth (laceration) and sexual reproduction in 2 populations of $M$. senile in habitats of high and low current regimes, and furthermore, to investigate whether frequencies of pedal laceration are regulated by the flow habitat, indicating phenotypic plasticity, or due to intrinsic factors within populations.

\section{MATERIALS AND METHODS}

Study sites. Gåsklåvan is a cove situated in the central part of the Gullmarsfjord with vertical rock walls facing NNE and reaching a depth of $70 \mathrm{~m}$ (Fig. 1). The cove is sheltered by tall emergent rock walls, and wave exposure and current velocity are generally low. From 0 to $15 \mathrm{~m}$ depth, Metridium senile is the dominant hard bottom species, covering 20 to $50 \%$ of the substratum when unexpanded. At increasing depth, $M$. senile is replaced, with respect to actiniarian dominance, by Protanthea simplex, but dense patches and clones of $M$. senile are found. $M$. senile is most abundant in the upper $15 \mathrm{~m}$ at a salinity of about $20 \%$ (Baltic water). Below $15 \mathrm{~m}$, the salinity increases to about $32 \%$ (North Sea water).

Strömmarna is an area of narrow channels connecting the Gullmarsfjord with the Koljofjord (Fig. 1). The channel chosen as an experimental site (Kâbergssund, Fig. 1) is 15 to $20 \mathrm{~m}$ wide and has nearly vertical rock walls to depths of 2 to $8 \mathrm{~m}$. The tidal amplitude on the Swedish west coast is small and generally does not exceed $30 \mathrm{~cm}$, but in the channel the current velocity is usually high. The current is irregular, bidirectional and generated by tides, winds and changing air pressures and may periodically reach $100 \mathrm{~cm} \mathrm{~s}^{-1}$. The rock walls are dominated by the blue mussel Mytilus edulis, numerous ascidians and large patches of sponges (Halichondria panicea and Haliclona sp.). A dense population of small ( 3 to $4 \mathrm{~cm}$ high), red-brown Metridium senile is found on the rock walls and on mussel beds on the bottom, covering almost $90 \%$ of the latter.

Field observations. The size distribution of Metridium senile at the 2 sites and at different depths was estimated by quadrat sampling. At Gåsklăvan, a $20 \mathrm{~m}$ transect line was deployed horizontally at each depth level ( 2 to $5,10,15$ and $20 \mathrm{~m}$ ) and 3 quadrats each measuring $50 \mathrm{~cm}$ by $50 \mathrm{~cm}$ were haphazardly selected. In each quadrat, the anemones were gently touched to provoke contraction, the number of specimens counted, and the pedal disc diameter (pdd, mean of largest and smallest basal diameter) measured using plastic calipers. At Strommarna, the size distribution was recorded only at 2 to $5 \mathrm{~m}$ depth, since this is the actual bottom depth range.

Transplantation experiments in situ. In July 1992, a $3 \mathrm{~m}$ long aluminium bar was mounted horizontally approximately $10 \mathrm{~cm}$ from a NNE facing vertical rock wall at $5 \mathrm{~m}$ depth in Råbergssund (Strömmarna) and at $15 \mathrm{~m}$ depth at Gåsklåvan (the Gullmarsfjord; Fig. 1). The rod was kept in position by means of 3 dowels plugged into holes drilled into the rock walls (see Svane 1988). Individuals of Metridium senile were haphazardly collected at each site by diving. The anenones were removed from the substratum using a 


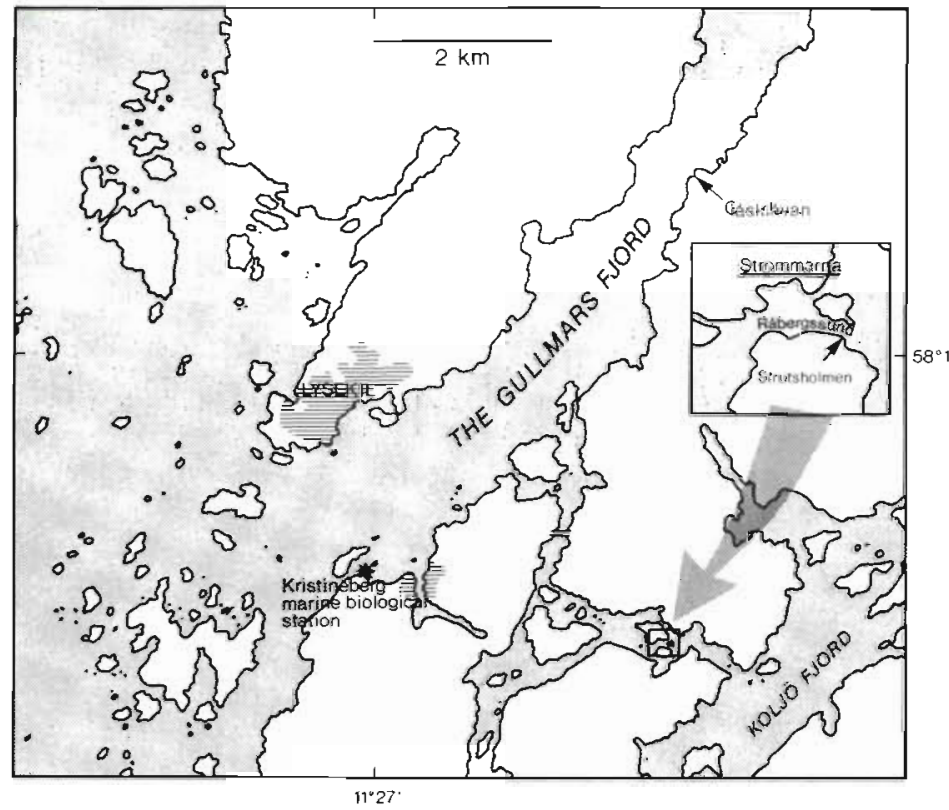

Fig. 1. Overview of the Gullmarsfjord on the west coast of Sweden and the study sites. The sites at Gåsklåvan and Strömmarna are indicated by arrows. The inset shows the exact location of the monitoring site at Strutsholm in Strömmarna

thin-bladed, blunt spatula in order to minimize tissue damage. The individuals were collected from as many clones within each population as possible by sampling widely spaced individuals (Shick et al. 1979, Hoffmann 1986). In the laboratory, specimens from each population were transplanted onto 12 asbestos panels each measuring 40 by $40 \mathrm{~cm}$. The anemones were allowed $48 \mathrm{~h}$ to establish themselves on the panels submerged on seawater tables. The panel populations were constructed to reflect size-frequency distributions equal to those of the natural populations (Kolmogorov-Smirnov 2-sample test, p > 0.05). After 48 h, 6 panels each contained a population of small $M$. senile from Råbergssund and 6 panels each carried a population of large $M$. senile from Gåsklåvan. The panels, submerged in seawater, were then transferred to the experimental sites and mounted aligned and rigidly below the rods in randomized order. At each site, 3 panels with approximately 20 individuals from Gåsklåvan and 3 panels with approximately 30 individuals from Strömmarna were suspended from the aluminium rods (Fig. 2). Since the panels were arranged on the same rod and all panels were used in the analysis, each panel constituted a pseudo-replicate according to Hurlbert
(1984). The pseudo-replicates were, however, considered to be independent due to a space of minimum $10 \mathrm{~cm}$ between the panels. Random and independent deployment of individual panels at the 2 sites would have been preferable but was not practically possible.

Before transplantation, an additional dowel was mounted $3 \mathrm{~m}$ from the end of the panel rack at each site along the same isobath, which provided support for an additional aluminium rod for stereophotography. Below the rod, 6 contiguous quadrats, each measuring 50 by $50 \mathrm{~cm}$, were selectively and loosely cleared of protruding epibioses, leaving spaced individuals of Metridium senile visible on photographs. At monthly intervals, all panels and quadrats were stereophotographed using the technique described by Svane (1988). Only the side of the panels facing away from the rock wall was photographed. The stereophotographs were analyzed in 2 aligned stereomicroscopes (Svane 1988), one equipped with a calibrated ocular micrometer.

The transplantation experiment was initiated in mid July 1992 and terminated 7 October (Expt I), and repeated from 13 October to 9 December 1992 (Expt II). Selective clearing of quadrats was not repeated, but monitoring of quadrats continued during part of Expt II.

Laboratory experiments: laceration at constant levels of low and high flow. In mid May 1992, approximately 100 individuals from each of the populations at Gåsklåvan and Strömmarna (using the sampling technique and considerations mentioned earlier) were collected, established on acrylic panels and subsequently transferred to 4 laboratory flow tanks supplied with
Strömmarna

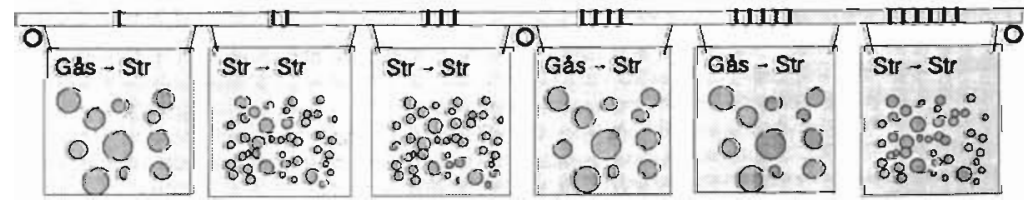

Gåsklâvan

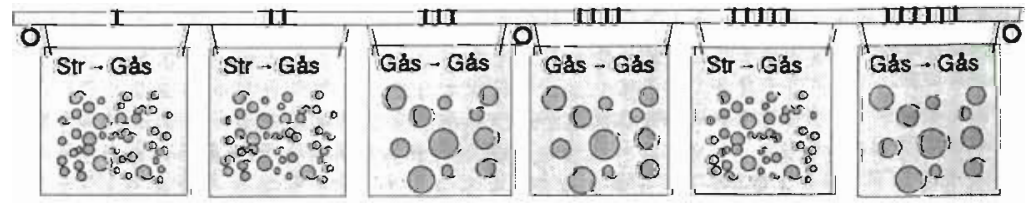

Fig. 2. Experimental design of transplantations of panel populations of Metridium senile at Gåsklåvan and Strömmarna. Panels were mounted on the aluminium bar in random order. Each panel measured 40 by $40 \mathrm{~cm}$ 
seawater in a closed circuit. About 50 individuals from each population were transplanted onto four 90 by $30 \mathrm{~cm}$ acrylic panels and were allowed $48 \mathrm{~h}$ to establish themselves prior to deployment in the flow tanks. Sizefrequency distributions of panel populations were determined as in the field. Separate panels with attached anemones from Gåsklåvan and Strömmarna were thereafter mounted in four $40 \mathrm{l}$ flow tanks where 2 tanks were preset at high $\left(>25 \mathrm{~cm} \mathrm{~s}^{-1}\right)$ and 2 at low $\left(<5 \mathrm{~cm} \mathrm{~s}^{-1}\right)$ flow, respectively. The flow through the tanks was maintained with powerful circulation pumps (Sacem 1200), producing an even (though not laminar) flow. The low-flow tanks shared a circulation pump set at $1 / 4$ the power of the high-flow tanks. All tanks were aerated and the water filtered through gravel filters (see Moe 1982). In all tanks, the panels were kept vertical and parallel to the flow. The animals were fed live Artemia nauplii every $48 \mathrm{~h}$, and every 2 wk $1 / 4$ of the water was renewed. Asexual reproduction (laceration) of the 4 cross-transplanted populations was monitored weekly for 2 mo by photographing the panels. The size-frequency distributions $(0.5 \mathrm{~cm}$ intervals of pedal disc diameter) of the panel populations before transplantation were compared to distributions after transplantation in order to examine effects of exposure. By regular census of lacerates and potential parents, mean monthly rates of asexual reproduction were determined analogous to the transplantations in situ. The trial was repeated during late October 1992 to early January 1993 with new panel populations.

Data analysis. The monitored panels and quadrat populations were scored for parent size (pedal disc diameter), number of parents and number of new individuals produced by laceration between dates of photographing. Only lacerated pedal disc fragments no longer connected to the parent were counted. Mean monthly rates of laceration were calculated as:

$$
\text { Laceration rate }=\frac{\Delta N_{\text {lac }}}{N_{\text {par }} \Delta t} 30
$$

where $\Delta N_{\text {lac }}=$ number of lacerations produced between days of monitoring, $N_{\mathrm{par}}=$ mean number of parents on the panels during that period, and $\Delta t=$ number of days between monitoring. Calculating the mean rate of laceration based on intervals between monitoring reduces biases from lacerate mortality and parent migration compared to a calculation based on a census before and after the experiment.

At the termination of each experiment, the rates of laceration of the transplanted parent populations were compared reciprocally by an analysis of variance (ANOVA) followed by the Student-Newman-Keuls (SNK) multiple comparison test (Sokal \& Rohlf 1969). A significance level of $\alpha=5 \%$ was used throughout the study. Since the conditions for the 2 successive labora- tory experiments were similar, the data were pooled, whereas the field experiments were treated separately.

Sexual reproductive cycle: oocyte size-frequencies. From the populations at Strömmarna and Gåsklåvan, 20 and 50 individuals respectively were collected at monthly intervals from May to October 1992. The same sampling technique and considerations mentioned earlier were applied in order to maximize the number of clones representing each population. The specimens were transferred to beakers where an isotonic solution of $\mathrm{MgCl}_{2}$ was gradually added in order to relax the musculature and allow fixation of the anemones while fully extended (Manuel 1988). When the anemones no longer responded to mechanical stimuli, they were transferred to Bouin's fixative, and a proportional amount of the fixative was injected into the coelenteron. Approximately $72 \mathrm{~h}$ later, the anemones were transferred successively to increasing concentrations of ethanol and were finally stored in a $70 \%$ solution.

From approximately mid-column, a 3 to $5 \mathrm{~mm}$ thick transversal disc was dissected from each female, since gonad size is largest in this region (Bucklin 1982). After dissection, individual preserved wet wt (ww) was determined after draining the anemone (including the dissected disc) on paper towels for 1 to $2 \mathrm{~min}$. The transversal discs were transferred to 2,2-dimethoxypropane to reduce shrinkage of the tissues during the succeeding paraffin-imbedding (Prento 1979). The discs were subsequently sectioned $8 \mu \mathrm{m}$ on a microtome and stained with Ehrlich's Hematoxylin-Eosin. In order to estimate the developmental stage and time of spawning, the largest and smallest diameters of 100 oocytes were measured from each female using a calibrated ocular micrometer isee Giese \& Pearse 1974, Bucklin 1982, Grant \& Tyler 1983a). The measurements were done on different sections and gonads from each specimen as a precaution against heterogenous development within an individual (Grant \& Tyler 1983a), and only oocytes with a nucleolus in the section were measured (Grant \& Tyler 1983b). Oocyte sizefrequencies were determined based on females from each sample. Only individuals larger than $2 \mathrm{~cm}$ pdd were included in order to exclude immature individuals from the analysis (Grant \& Tyler 1983a). Median oocyte sizes were tested for differences in location between the populations by the non-parametric Kruskal-Wallis test (Sokal \& Rohlf 1981).

Sexual reproductive allocation. To estimate the relative contribution to sexual reproduction of the 2 populations, transverse sectional gonad areas (TSGA) of female gonads as a function of preserved wet body wt (see Bucklin 1987) were used. Measurements of TSGA were made by means of a calibrated ocular micrometer on sections from the mid-column of 10 mature females from Gåsklåvan and 8 mature females from Ström- 
marna collected prior to spawning. To exclude immature females, only individuals with a pedal disc diameter larger than $2 \mathrm{~cm}$ (ww $\sim 0.3 \mathrm{~g}$ ) were included. Largest and smallest diameter of each ovary in each section were measured and the total cross-sectional gonad area was determined from the sum of gonad areas. This method provided a relatively coarse estimate of ovary area because not all transverse discs were intact, and in these latter cases total ovary area was estimated by extrapolation. Since gonad size is not a linear function of adult size in Metridium senile (Bucklin 1987), sexual reproductive allocation could not be compared using gonad indices based on body size (e.g. Bucklin 1982, Giese \& Pearse 1974). Instead, TSGAs were compared between sites using an analysis of covariance (ANCOVA) on log-transformed data with preserved wet $w t(w w)$ as the covariate (TSGA = $a w w^{b}$; Sokal \& Rohlf 1981, Grant \& Tyler 1983a).

Conversion of preserved wet weight to pedal disc area. For use in interconverting pdd and ww, a conversion curve was constructed. The attached pdd of 95 individuals from harbor pilings at the Kristineberg Marine Research Station were measured individually (mean of largest and smallest pedal disc diameter) before collecting. The specimens were grouped into pdd size classes of $0.5 \mathrm{~cm}$ intervals, preserved in $10 \%$ formalin and washed in $70 \%$ ethanol $48 \mathrm{~h}$ later. Corresponding values of pdd and ww were plotted in a loglog graph $\left(p d d=a w w^{b}\right)$, and the relationship was tested by linear regression analysis (Fig. 3).

Flow measurements in situ. In order to quantify the accumulated flow exposure experienced by the panel populations in the field, a technique developed by Muus (1968) was applied. Weight loss per unit of time

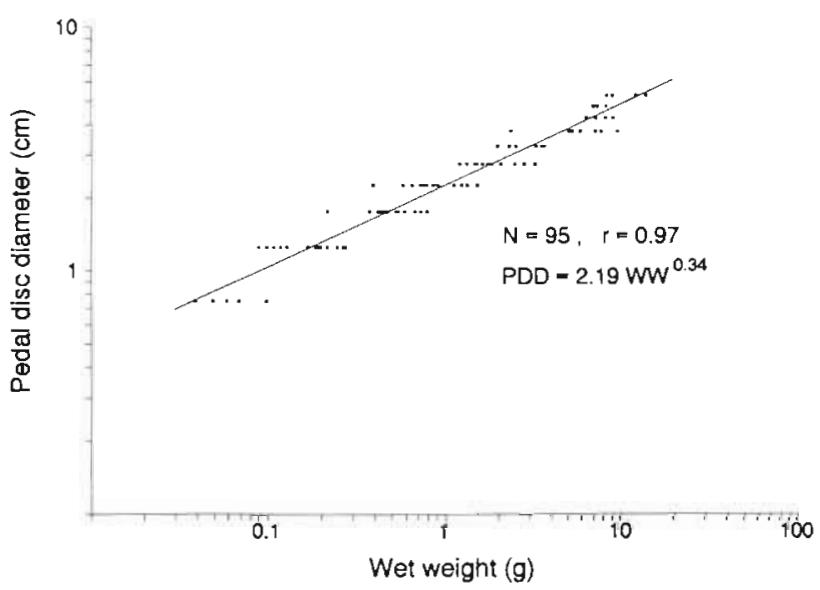

Fig. 3. Metridium senile. Log-log regression of pedal disc diameter and wet weight of 95 individuals. Attached pdd was measured before collecting the animals. The expected power function relating pdd to preserved wet wt (ww) fitted significantly to the data $(F s=1921.4, \mathrm{p}<0.001)$ of plaster balls was used as a measure of the mean current velocity irrespective of direction of flow. Plaster balls moulded on metal wires were weighed dry before exposure, mounted at a distance of approximately $10 \mathrm{~cm}$ from each panel, and collected after 24 to $96 \mathrm{~h}$ of exposure. The plaster balls were then dried for $72 \mathrm{~h}$ at $60^{\circ} \mathrm{C}$ and the weight loss per $24 \mathrm{~h}$ of exposure calculated. Six batches of 3 balls each were exposed for 6 to $24 \mathrm{~h}$ in a flume at various, constant current velocities measured by thermistor probes to estimate weight loss as a function of flow velocity. The resulting calibration curve was used to determine the approximate mean current velocity from the weight loss of plaster balls exposed in situ.

\section{RESULTS}

\section{Field observations}

The densities of the natural populations of Metridium senile at the 2 sites were estimated to be $470 \pm 21$ ( $\mathrm{SE}, \mathrm{n}=3$ ) ind. $\mathrm{m}^{-2}$ at $5 \mathrm{~m}$ depth, decreasing to $104 \pm 19$ $(\mathrm{n}=3)$ ind. $\mathrm{m}^{-2}$ at $20 \mathrm{~m}$ depth, at Gåsklåvan and 25000 $\pm 2200\left(\mathrm{n}=3\right.$ ) ind. $\mathrm{m}^{-2}$ at Strömmarna. Estimates are based on a photogrametric analysis at Gåsklåvan (see Svane 1988) and in situ recordings of anemones in $0.25 \mathrm{~m}^{2}$ quadrats, haphazardly selected on the bottom of the Rảbergssund channel in Strömmarna.

The size-frequency distributions of pedal disc diameters in the 2 studied populations, at 2 to $5 \mathrm{~m}$ depth in Strömmarna and at $5,10,15$, and $20 \mathrm{~m}$ depths at Gåsklåvan, are shown in Fig. 4. Comparisons of distributions between sites at $5 \mathrm{~m}(2$ to $5 \mathrm{~m}$ ) were significantly different (Kolmogorov-Smirnov 2-sample test, $p<0.01$ ). Median pdd at Strömmarna was only $0.3 \mathrm{~cm}$, with more than $80 \%$ of the population consisting of individuals $<0.5 \mathrm{~cm}$ pdd, which were mainly lacerates not yet regenerated. Only $4 \%$ had a pdd $>1 \mathrm{~cm}$, and the largest size class $(2.0 \mathrm{~cm} \pm \mathrm{pdd}<2.5 \mathrm{~cm})$ was only represented by 2 individuals. At Gåsklávan, a marked difference in size-frequency distribution in relation to depth was also observed (Kolmogorov-Smirnov 2sample test, $p<0.01$, Fig. 4). Small anemones dominated at depths of 2 to $5 \mathrm{~m}$ and $10 \mathrm{~m}$ (median pdd 0.7 and $1.3 \mathrm{~cm}$, respectively), whereas larger anemones became more dominant with increasing depth (median pdd 2.5 and $3.5 \mathrm{~cm}$ at 15 and $20 \mathrm{~m}$, respectively). Flow velocity at the panels was considerably higher at Strömmarna than at Gåsklåvan $(15 \mathrm{~m}$, Table 1). Additional flow measurements along the vertical transect at Gåsklåvan showed no significant difference in flow velocity between the 4 water depths (not shown). At Strömmarna, the mean flow velocity was higher than $65 \mathrm{~cm} \mathrm{~s}^{-1}$ at all measurements, which was 

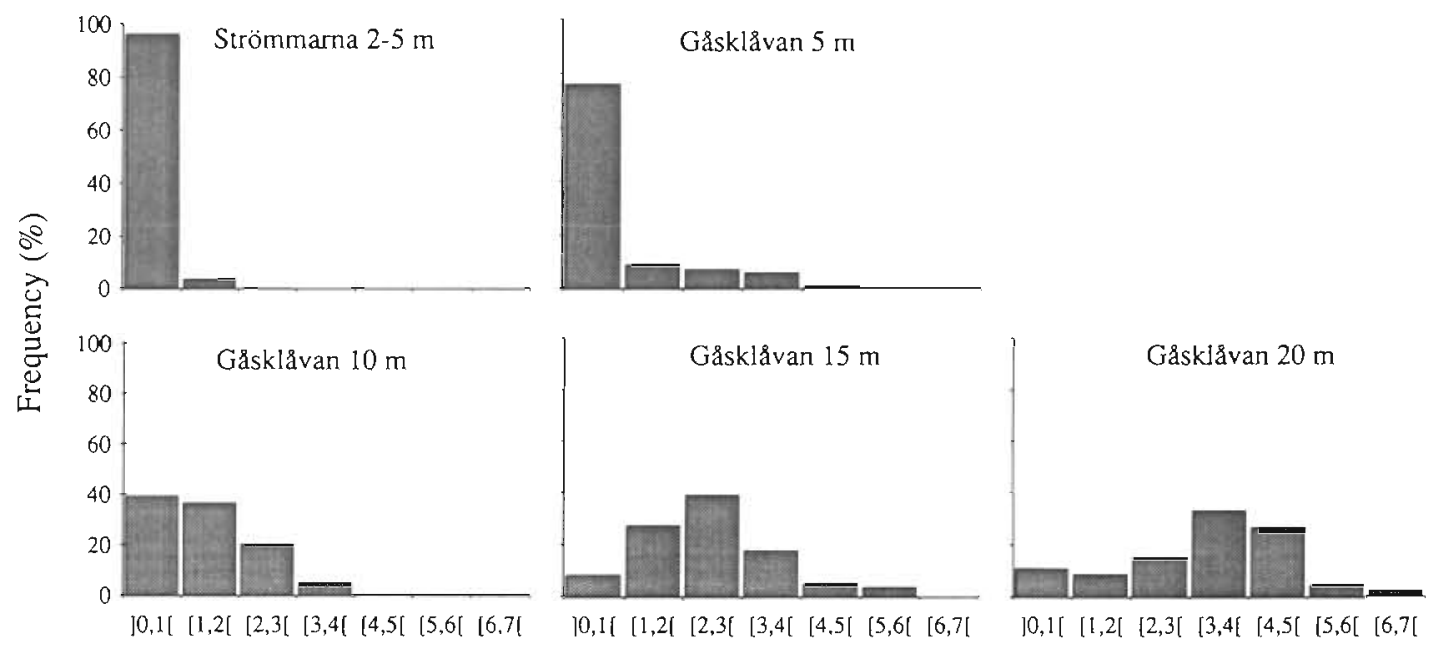

Pdd size classes $(\mathrm{cm})$

Fig. 4. Metridium senile. Size-frequency distributions of pedal disc diameter (pdd) in natural populations from Strömmarna at 2 to $5 \mathrm{~m}$ and from Gåsklåvan at $5,10,15$, and $20 \mathrm{~m}$, respectively. Body size was larger at Gåsklåvan ( $5 \mathrm{~m}$ ) compared to Strömmarna, and increased with depth at Gåsklåvan (all significant by the Kolmogorov-Smirnov 2-sample test, $p<0.01$ )

the maximum obtainable velocity in the flume during calibration of the plaster balls. During 2 surveys at Strömmarna, flow velocity was estimated to be higher than $100 \mathrm{~cm} \mathrm{~s}^{-1}$. Mean flow velocity at Gåsklåvan was $3 \mathrm{~cm} \mathrm{~s}^{-1}$, never exceeding $6 \mathrm{~cm} \mathrm{~s}^{-1}$.

\section{Laceration on natural substratum}

On the 6 quadrats of selectively cleared natural substratum at Gåsklåvan, pedal laceration was virtually absent. Only 2 lacerates among 62 potential parental individuals were observed from August 19 to October 27, giving a final ratio of produced pedal lacerates per potential parental individual of 0.03 . In Strömmarna, it was unfortunately not possible to monitor individual pedal laceration on natural substratum due to the migration of mussels into the cleared

Table 1. Weight loss per $24 \mathrm{~h}$ of plaster balls deployed at the 2 sites and the corresponding mean current velocity. Flow speeds higher than $65 \mathrm{~cm} \mathrm{~s}^{-1}$ could not be measured, since this was the maximum velocity in the flume during calibration

\begin{tabular}{|c|c|c|c|c|}
\hline \multirow[t]{2}{*}{ Exposure } & \multicolumn{2}{|c|}{ GåskIåvan } & \multicolumn{2}{|c|}{ Strömmarna } \\
\hline & $\begin{array}{c}\text { Mean } \\
\text { weight loss } \\
\left(\mathrm{g} 24 \mathrm{~h}^{-1}\right)\end{array}$ & $\begin{array}{l}\text { Current } \\
\text { velocity } \\
\left(\mathrm{cm} \mathrm{s} \mathrm{s}^{-1}\right)\end{array}$ & $\begin{array}{l}\text { Mean } \\
\text { weight loss } \\
\left.\text { (g } 24 h^{-1}\right)\end{array}$ & $\begin{array}{l}\text { Current } \\
\text { velocity } \\
\left.(\mathrm{cm} \mathrm{s})^{-1}\right)\end{array}$ \\
\hline 1 & 3.65 & 5.7 & 21.4 & $>65$ \\
\hline 2 & 3.29 & 4.7 & 18.9 & $>65$ \\
\hline 3 & 3.08 & 4.2 & 18.5 & $>65$ \\
\hline 4 & 2.60 & 3.1 & 15.2 & $>65$ \\
\hline 5 & 2.11 & 2.1 & & \\
\hline
\end{tabular}

patches and heavy colonization by colonial ascidians and sponges, eventually occupying more than $50 \%$ of the quadrat areas after 2 mo and consequently obscuring the view.

\section{Transplantation experiments in situ}

The results of the 2 field transplantation experiments are shown in Fig. 5A, B. Strömmarna individuals consistently produced more lacerates. When Strömmarna individuals were transfered to Gaskklavan, the rate of laceration decreased significantly, whereas laceration rates were unaffected among Gåsklåvan individuals when transplanted to Strommarna. The ANOVA showed a significant effect of treatment in both experiments (Table 2). In all panel populations, it was observed that predominantly the larger anemones were undergoing frequent laceration. Differences in size-specific amount of laceration within panel populations could not be quantified, however, as locomotion and frequent crossing of trails of lacerates obscured the analysis.

At both sites, fragmentations of the pedal disc were discrete, periodical events. It was observed that an anemone produced up to 15 lacerations (new modules) in less than $2 \mathrm{wk}$. Individuals typically extended the pedal disc to cover a large area (compared to the area of the tentacle crown), and detached fragments in a ring around the pedal disc. Within $1 \mathrm{wk}$, the ring separated into a larger number (10 to 15 ) of regenerating units. Some anemones showed extensive locomotion, leaving a trail of fragments on the panel, but other 
Fig 5. Metridium senile. Two reciprocal transplants at Strommarna (S) and Gåsklåvan (G). The figure shows monthly mean rate of laceration per individual $\pm 95 \%$ confidence limits of $\mathrm{n}=3$ panels. Underlined transplants are not significantly different by the SNK test. Expt I (A.) was run July to October 1993 and Expt II (B) was run October to December 1993. Transplant initials denote site of origin and site of exposure, respectively

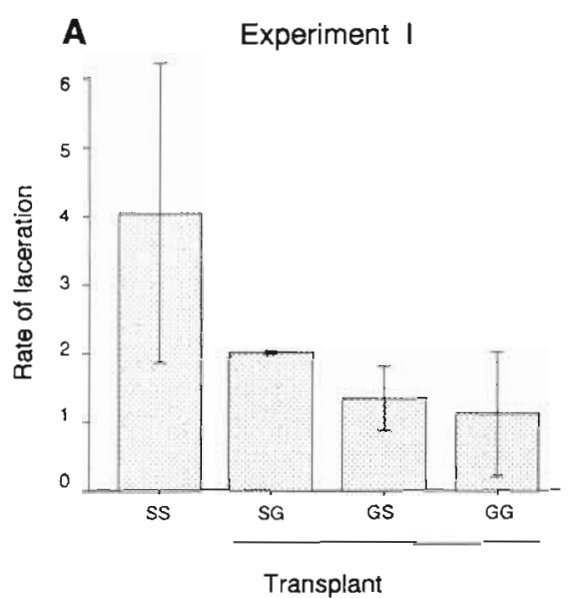

B Experiment II

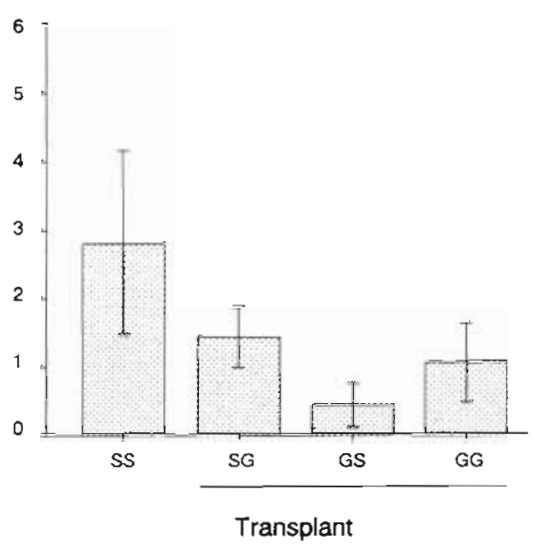

anemones were stationary throughout the period of the experiment and were not seen lacerating. Size frequency distributions of any panel population did not change significantly when transplanted to an altered flow habitat (Kolmogorov-Smirvov 2-sample test, p > $0.05)$.

\section{Laboratory experiments: laceration at constant levels of low and high flow}

Individual anemones from Strömmarna produced more than twice the amount of lacerations per parental individual during the experimental period than did individuals from Gåsklåvan, irrespective of flow regime (Fig. 6). The analysis of varrance showed a significant treatment effect (Table 2), and the SNK-test revealed that Strömmarna individuals produced significantly more lacerates than Gåsklåvan individuals (Fig. 6).

Table 2. Metridium senile. One-way ANOVA of laceration data. $" p<0.05 ; \cdots p>0.01$

\begin{tabular}{|lrrrrc|}
\hline Source of variation & df & SS & MS & FS & p \\
\hline Expt I & & & & & \\
Transplant & 3 & 16.13 & 5.38 & 7.63 & 0.0098 \\
Error & 8 & 5.63 & 0.70 & & $\cdots$ \\
Total & 11 & 21.76 & & & \\
Expt II & & & & & \\
Transplant & 3 & 9.11 & 3.04 & 10.16 & 00042 \\
Error & 8 & 2.39 & 0.30 & & $\cdots$ \\
Total & 11 & 11.50 & & & \\
Laboratory & & & & & \\
Transplant & 3 & 31.45 & 10.48 & 906 & 0.0295 \\
Error & 4 & 4.63 & 116 & & $\cdot$ \\
Total & 7 & 36.08 & & & \\
\hline
\end{tabular}

\section{Sexual reproduction: period of spawning and reproductive allocation}

A total of 140 individuals were collected at Gåsklåvan and 350 at Strömmarna for sexual reproductive analysıs. More animals were collected from Strömmarna, as only a few clones apparently dominated there, and the first samples indicated a skewed sex ratio with a preponderance of males. Despite extensive sampling at Strommarna, it was not possible to obtain more than 2 females in most samples and no females were found in the October sample. The sex ratio at Strömmarna was found to be $1: 8$ compared to $1: 1.4$ at Gåsklăvan. However, the estimated sex-ratıo at Strömmarna was based on large individuals only. Sampling at Gåsklåvan was more representative with a mean preserved wet wt of $10 \mathrm{~g}$ and a pedal disc diameter of $4 \mathrm{~cm}$, as this size class dominated the population.

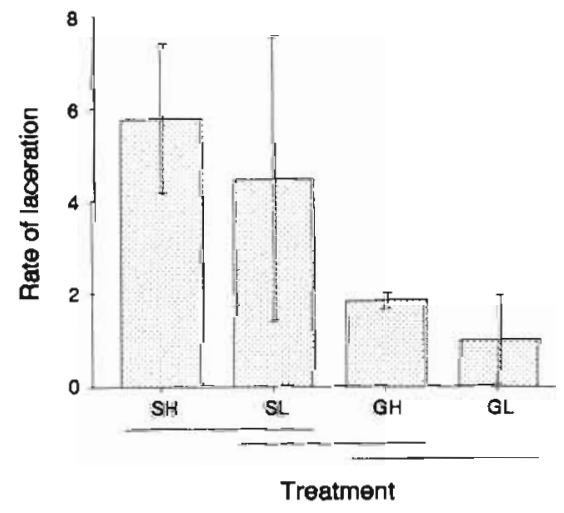

Fig. 6. Metndium senile. Laboratory experuments. Cåsklåvan (G) and Strommarna (S) panel populations exposed to high $(\mathrm{H})$ and low $(\mathrm{L})$ flow velocity in flow tanks. Mean monthly rates of laceration per individual $\pm 95 \%$ confidence lumits of 2 successive experuments are shown Groups with a common underline are not significantly different by the SNK test 

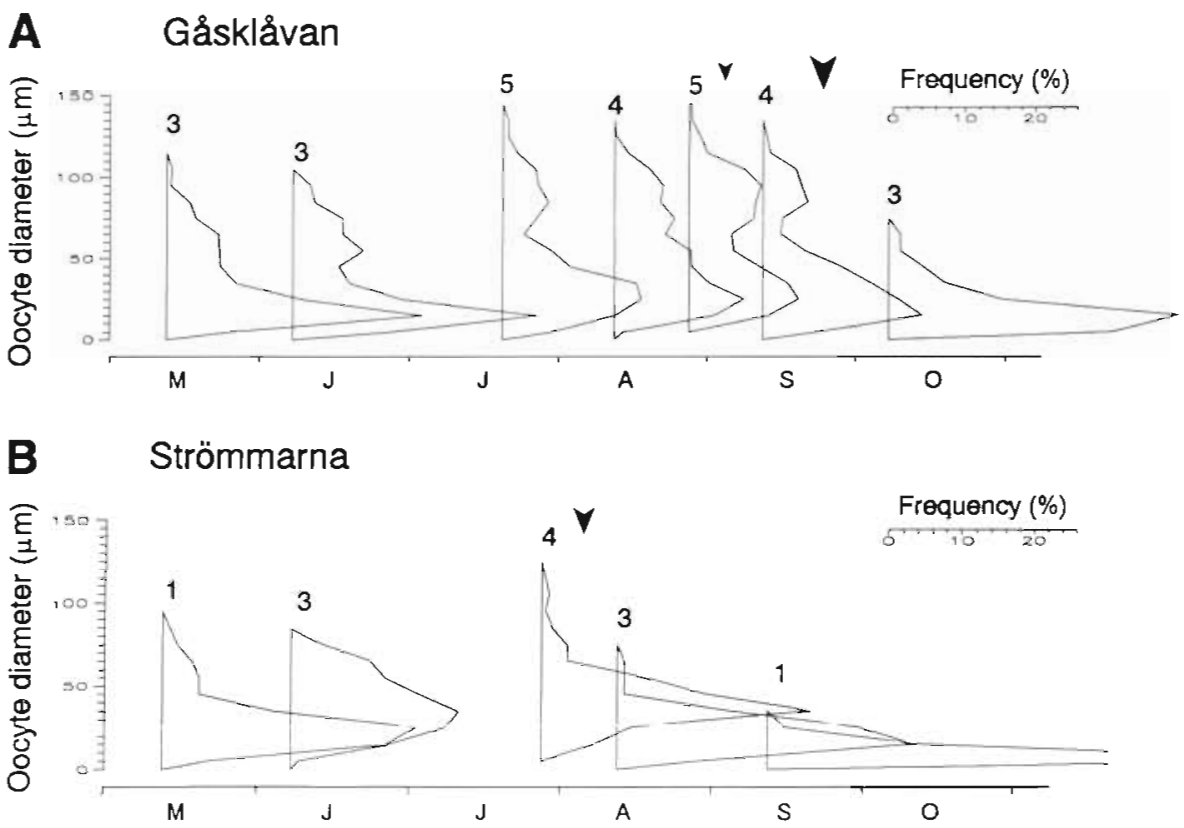

Fig. 7. Metridium senile. Oocyte size-frequency distributions of monthly samples from (A) Gåsklåvan and (B) Strömmarna, May-October 1992. The number on top of each polygon is the number of females in the sample. Arrows indicate spawning. Median oncyte diameter was significantly larger at Gåsklávan (Kruskal-Wallis test, $\mathrm{p}=0.046$ )

In the Gåsklåvan population, mature oocytes were present from the begining of June until September (Fig. 7), and spawning occured in late August and early September. At Strommarna, spawning apparently occurred 1 mo earlier (July). The median oocyte diameter of monthly samples was significantly larger at Gåsklåvan compared to Strömmarna females (KruskalWallis test, $\chi^{2}{ }_{1}=3.98, p=0.046$; Figs. $7 \& 8$ ). Unfortu-
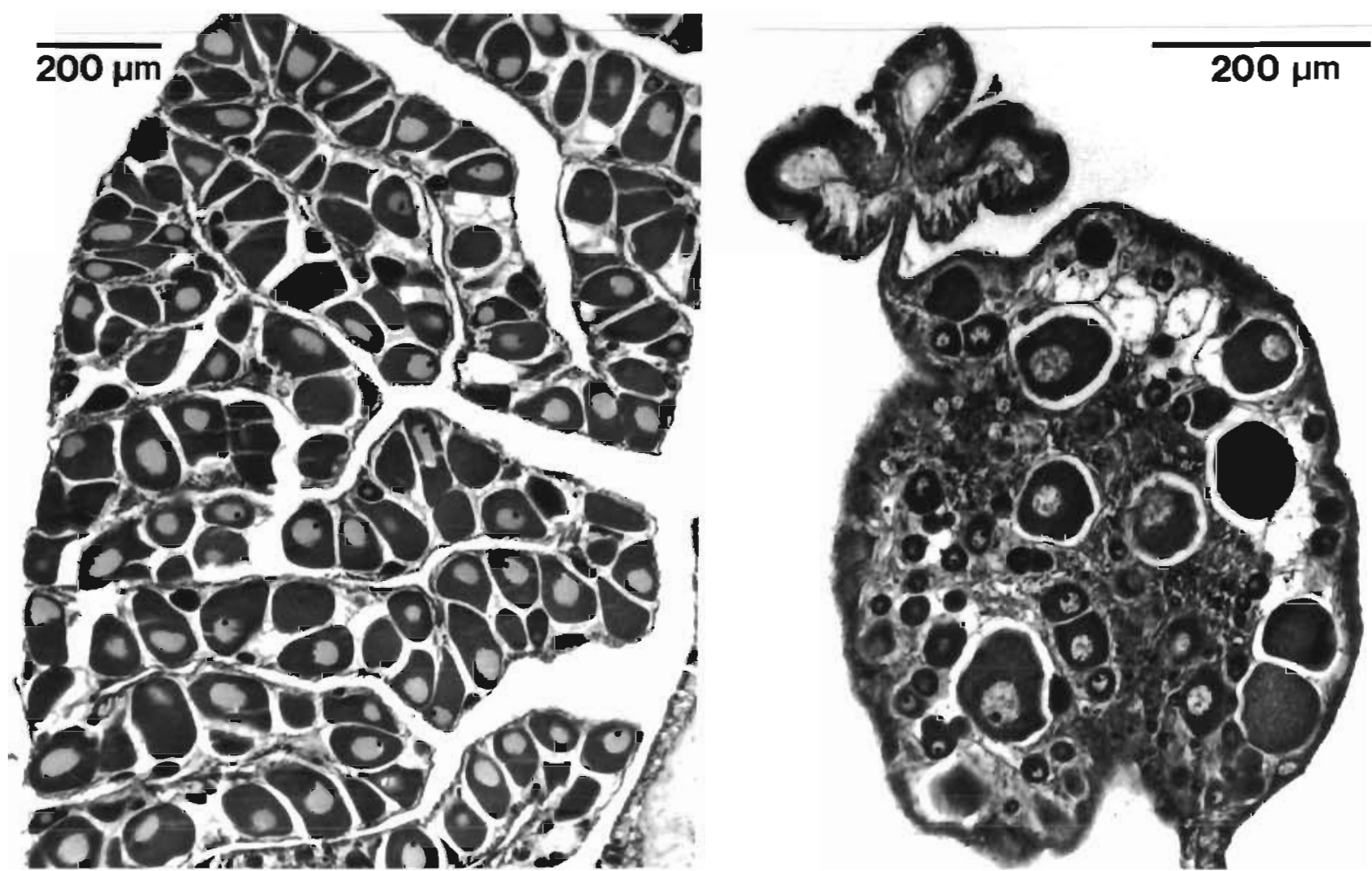

Fig. 8. Metridium senile. Transverse section of ovary from a Gảsklåvan female (left, wet wt $=15 \mathrm{~g}$ ) and a Strömmarna female (right, wet $w t=2.6 \mathrm{~g}$ ), collected prior to spawning (July and August, respectively). The sectional area of the ovary and percent age of mature oocytes $(>100 \mu \mathrm{m})$ is larger for the Gåsklåvan female. Photos: Jørgen Lützen 
Table 3. Metridium senile. ANCOVA of transverse sectional gonad areas. ns: not significant.

\begin{tabular}{|lrcccc|}
\hline Source of variation & df & SS & MS & FS & p \\
\hline $\begin{array}{l}\text { Log (adjusted means) } \\
\text { Error (deviations } \\
\text { from a common slope) }\end{array}$ & 15 & 0.12 & 0.12 & 1.47 & $0.2461^{\text {ns }}$ \\
\hline $\begin{array}{l}\text { Estimated log (adjusted } \\
\text { means) } \pm \text { SE }\end{array}$ & $0.97 \pm 0.11$ & $0.65 \pm 0.21$ \\
\hline
\end{tabular}

nately, no sampling was done in Strömmarna in late June or early July. In that period, samples may have contained females with a greater proportion of larger oocytes and the onset of spawning may consequently have occured earlier than at the end of July. Only 2 females (small individuals $<4 \mathrm{~g}$ ) were scored as infertile in the Gåsklåvan samples, while a large proportion of the samples from Strömmarna were infertile, particularly individuals smaller than $0.5 \mathrm{~g}$. Spent females were recognized in the August samples from Strömmarna and in the October samples from Gåsklåvan.

The 2 populations of females were not different in terms of transverse sectional gonad area (TSGA) when adjusted for a common body weight (Table 3, Fig. 9). Linear regression of $\log (\mathrm{TSGA})$ on $\log (\mathrm{ww})$ was highly significant for both samples (Gåsklåvan: $F s_{(1,8)}=63.2$, p $<0.001$; Strömmarna: $\left.F_{S_{(1,6)}}=19.80, p=0.004\right)$, and the slopes did not differ significantly $\left(F s_{(1,14)}=0.053\right.$, $p=0.82$ ), thus meeting the assumptions for the ANCOVA. The power functions (TSGA $=a w^{b}$ ) provided a good fit to the data (Strömmarna: $r=0.88$, Gåsklåvan: $r=0.94$; Fig. 9) and exponents of 1.8 and

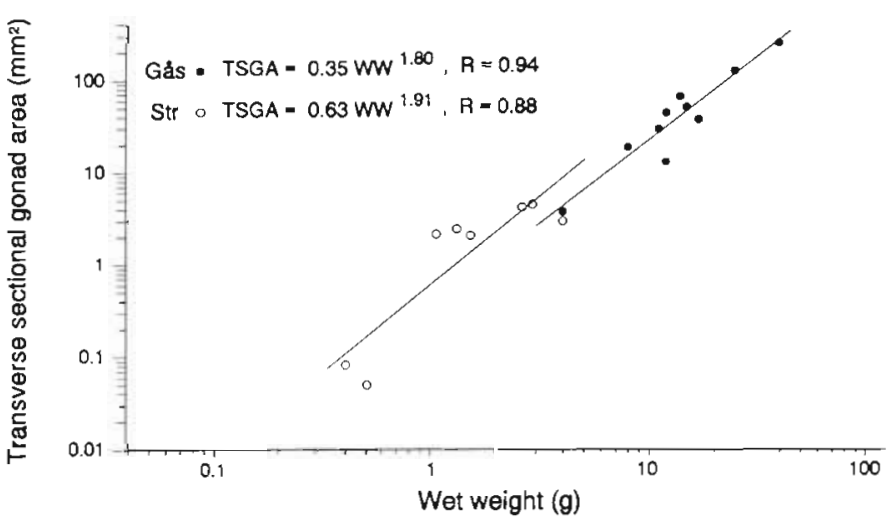

Fig. 9. Metridium senile. Log-log regression of transverse sectional gonad area (TSGA) of 10 females from Gåsklåvan and 8 females from Strömmarna, sampled prior to spawning, on preserved wet wt (ww). Difference in ISGA was insignificant between populations when adjusted for a common ww (see Table 3)
1.9, respectively, indicated that transverse sectional gonad area nearly doubled with increasing increments of preserved wet wt. Mean gonad index (based on TSGA/pedal disc area) was therefore significantly larger among the Gåsklåvan females compared to Strömmarna females (Fig. 8).

\section{DISCUSSION}

The size of Metridium senile can be related to its habitat. The small morph, or variety, previously named $M$. senile pallidum $(<2.5 \mathrm{~cm}$ pdd; expanded column height $<\sim 5 \mathrm{~cm}$ ), is found in areas of high current regimes but also at shallow depths along the sheltered rocky shores on the Swedish west coast (Fig. 4). The large morph, previously named $M$. senile dianthus ( $>2.5 \mathrm{~cm}$ pdd expanded column height $>5 \mathrm{~cm}$ ), which may reach an expanded individual column height of more than $30 \mathrm{~cm}$, is found at greater depths. No individuals are found intertidally since tides are negligible along the Swedish west coast.

The observed differences in body size may be genetically determined (Fautin et al. 1989). Genotypic differences may interact with environmental factors, however, to produce the observed differences in body size and population structure (Shick et al. 1979). Several hypotheses, not necessarily mutually exclusive, have been suggested to explain habitat-related differences in size-distributions and have been reviewed by Shick (1991): (1) In fast current habitats, size is constrained by mechanical limitations of the anemone's body plan (Shick et al. 1979, Shick \& Hoffmann 1980). (2) Asexual reproduction (laceration rate) increases with current speed resulting in a small body size (Shick \& Hoffmann 1980, Bucklin 1987). (3) Differential predation by the nudibranch Aeolidia papillosa on small individuals affects the size-structure of anemone populations (Harris 1973, 1986, Shick et al. 1979).

The results of the transplantation experiments in situ indicated that Strommarna animals produced consistently more lacerations than Gasklavan individuals in high flow, but reduced their rates of laceration when transplanted to the lowflow habitat. Conversely, Găsklåvan individuals did not increase laceration rates when transplanted to the high-flow site in Strömmarna (Fig. $5 \mathrm{~A}, \mathrm{~B}$ ). A relatively high mean laceration rate was maintained by the transplanted Strömmarna individuals but due to the large variation among (pseudo-) replicates this was not significantly different from Gåsklåvan individuals. The laboratory experiments showed a slightly different pattern where Gåsklåvan individuals maintained low laceration rates while Strommarna individuals 
maintained high laceration rates irrespective of flow regime (Fig. 6). However, within the results of the laboratory experiments there is a tendency, although not statistically significant, for the Strömmarna individuals to decrease their laceration activity when kept in low flow. The conclusion is, accordingly, that laceration rates are influenced to some extent by current speed, but that Strömmarna individuals maintain a higher laceration rate indicating an intrinsic difference between populations. Whether this difference is genetic or due to phenotypic plasticity coupled with a time lag is, however, not conclusive from our results. If rate of laceration is only a function of flow exposure on the anemone body plan, Gåsklåvan anemones would have been expected to produce more lacerates in high flow than Strömmarna individuals in low flow, due to the proportionately greater drag in large individuals (Wainwright \& Koehl 1976, Koehl 1977, 1982). In addition to the different responses to flow, there seemed to be a marked effect of transplantation to a new substratum per se on the rate of laceration, at least within the Gåsklåvan population. Gås $\rightarrow$ Gås panel populations produced a significant number of lacerates relative to the almost negligible laceration rate exhibited by the undisturbed anemones on the rock wall (only 2 lacerates per 62 adults during $2 \mathrm{mo}$ ), suggesting that the change of substratum produced a larger increase in laceration activity than the change of flow habitat.

In the Gullmarsfjord area, a marked abundance of small sized Metridium senile is associated with fast current habitats. However, small individuals are also found abundantly in shallow sheltered sites where the mean body size increases with depth (Fig. 4). Wave exposure of some degree may cause a higher mean flow velocity in these habitats compared to deeper sites inhabited by large morphs, but only close to the surface $(1$ to $2 \mathrm{~m})$. In the fast current sites at Strömmarna, current velocities above $100 \mathrm{~cm} \mathrm{~s}^{-1}$ are common and the small morph dominates. Large morphs transplanted to Strömmarna managed to expand their tentacle crowns, apparently feeding, but the column was kept short and within the height range of the small morphs, indicating some mechanical constraints. The experiments were performed in August to October but the panels with the transplanted anemones were left and revisited during May the following year. At Strömmarna, the individual animals were still on the panels and no reduction in size of the large Gassklåvan anemones was evident. At Gâsklâvan, only few anemones were still located on the panels in May.

The predatory nudibranch Aeolidia papillosa is found abundantly in the high current site in Strömmarna, where it feeds vigorously on Metridium senile. At the sheltered Gåsklåvan it is rarely found. It seems therefore unlikely that differential feeding on small individu- als of $M$. senile by $A$. papillosa should influence the sizedistribution of anemones by increasing the mean size as suggested by Harris $(1973,1986)$, since the predator is rarely found among larger anemones.

The observed patterns of size-distribution in Metridium senile in the Gullmarsfjord are to some extent in accordance with observations made in North America and the British Isles. However, these patterns have been related to distribution in intertidal versus subtidal environments (Bucklin 1987) or high versus low current regimes (Shick et al. 1979. Shick \& Hoffmann 1980). In the sheltered Gullmarsfjord, a pattern of size distribution, where small individuals occur in the high subtidal, and where the mean body size increases with depth, can be observed (Fig. 4). Tidal currents are virtually absent and turbulence by wave action is limited to the surface thereby reducing the plausibility of current velocity as the sole factor explaining the observed size-distribution pattern. Since current velocity and other physical factors (temperature, salinity), as well as fouling rate (Svane pers. obs.), are influenced by site and depth, a likely general explanation for the observed size-distribution pattern is that stress stimulates pedal laceration, subsequently reducing the mean body size. This is supported by the fact that manipulation and transplantation to an artificial substratum (a type of physical stress or perturbation) had a marked effect on laceration, and by the results of Wahl (1985) who showed that individuals of $M$. senile transplanted to horizontal panels initially migrated, leaving trails of lacerates prior to reestablishment.

Based on its colour-monomorphic appearance and a sex ratio of 1 female to 8 males, indicating a low genotypic diversity, the Strömmarna population presumably consist of only a few clones proliferating extensively by clonal growth (see Williams 1975, Hoffmann 1976, 1986, Shick 1991). Populations of anthozoans with predominantly sexual reproduction are expected to have high genotypic diversities and a sex ratio of $1: 1$ (Shick 1991). This seems to be the case for the Gåsklåvan population at $15 \mathrm{~m}$ depth where the sex ratio was found to be $1: 1.4$ with a slight dominance of males. At this site several colour morphs are found, although the brown morph dominates at $15 \mathrm{~m}$ of depth and above.

Individual Gåsklåvan females produced significantly larger amounts of mature oocytes than Strömmarna females (Figs. $7 \& 8$ ). The size at which oocytes of Metridium senile have been reported to be ripe is 100 to $173 \mu \mathrm{m}$ (Gemmill 1920, Rawlinson 1934, Bucklin 1982, Shick 1991). Oocytes larger than $100 \mu \mathrm{m}$ in diameter were found only in late July at Strommarna and constituted less than $2 \%$ of the oocytes in the sample (Fig. 7B), whereas oocytes above that size made up 5 to $14 \%$ of the samples from July to September at Gåsklå- 
van (Fig. 7A). In terms of mature oocytes, or potential gametes, the Strömmarna females were mostly infertile. The results showed, however, a marked difference between the 2 populations with respect to individual size at sexual maturity. All females from Gåsklåvan smaller than $3 \mathrm{~g}$ preserved wet wt were infertile, whereas all females from Strommarna weighing 1 to $4 \mathrm{~g}$ were fertile. Others (Rawlinson 1934, Stephenson 1935, Shick \& Hoffmann 1980) have observed sexual maturity in small individuals of $M$. senile $(<1 \mathrm{~cm}$ pdd) from intertidal and from subtidal high-flow habitats. However, all females included in this analysis of oocyte size frequencies were larger than $2 \mathrm{~cm}$ pdd and were considered adults. Differences in the proportion of mature to immature oocytes per female between habitats prior to spawning are unlikely to reflect differences in body weight, since oocyte sizes are generally independent of adult body size (Grant \& Tyler 1983b).

Since gonad sizes among the Strömmarna females were not smaller than those expected for Gåsklåvan females with the same body weight, the high-flow regime does not seem to suppress sexual reproduction of the individual (ramet) per se. Adopting the view that asexual reproduction is a means of genet growth, rather than a mode of reproduction (Williams 1975, Sebens 1979, 1982, Hughes \& Cancino 1985, Pearse et al. 1989, Shick 1991), the following calculations will provide an approximate estimate of the number of $1 \mathrm{~g}$ female clonemates (ramets) from Strömmarna needed to produce a sexual reproductive output equal to that of a single $20 \mathrm{~g}$ Gåsklåvan female.

Reproductive allocation is often expressed as the relative gonad weight or volume (e.g. Giese \& Pearse 1974. Calow 1979, Begon et al. 1986). In sea anemones having gonads that can be modelled as long, elliptical columns (see Sebens 1981b), the volume of the gonads $\left(V_{g}\right)$ can be estimated as

$$
V_{\mathrm{g}}=L_{\mathrm{g}} \cdot \mathrm{TSGA}
$$

where $L_{\mathrm{g}}$ is the mean length of the gonads, and TSGA is the transverse sectional gonad area. Due to the notoriously variable height of the column in Metridium senile, gonad length is impossible to determine empirically, but the latter is here assumed to be approximately equal to the diameter of the pedal disc (pdd). This assumption is somewhat justified by the (mean) 1:1 ratio of column height to pedal disc diameter (Fautin et al. 1989) and the tendency toward isometric growth in M. senile (Sebens 1981a, Shick 1991). Hence

$$
V_{\mathrm{g}} \approx \mathrm{pdd} \cdot \mathrm{TSGA}
$$

By multiplying transverse sectional gonad area with the corresponding pedal disc diameter of a $1 \mathrm{~g}$ Strömmarna female and a $20 \mathrm{~g}$ Gåsklåvan female (combining Figs. $3 \& 9$ ), the ratio $V_{\text {głGảs })} / V_{g(\text { Str })}$ approaches 340.
That is, in order for a clone of $1 \mathrm{~g}$ females from Strömmarna to have the same sexual reproductive output as a single $20 \mathrm{~g}$ female from Gåsklåvan, it needs to consist of more than 300 ramets. The apparently few dominant clones at Strömmarna, however, probably consist of more than a million members, so only a small number of gametes per ramet is needed for the clone to have a reproductive output comparable to that of a small clone of large anemones. Growth to a large clonal biomass by frequent laceration may thus eventually (despite a low sexual output per ramet) be translated into increased sexual reproductive success (Sebens 1979, Shick et al. 1979, Pearse et al. 1989).

Since the sexual reproductive allocation of individual anemones at Strömmarna is much reduced as a consequence of the smaller body size, laceration (clonal growth) may be an equally (or even more) important component of fitness in extreme high flow habitats. The frequent deposition of asexual progeny may serve a double function in both spreading and reducing the risk of genet mortality (an alternative currency of fitness compensating for the reduced sexual output; Williams 1975, Hughes \& Cancino 1985) as well as in maintaining the small body size necessary for efficient feeding in high-flow regimes (Koehl 1977 , 1982, Shick 1991).

The size-frequency distributions of the Gåsklåvan and Strömmarna populations do not seem to represent 2 different habitat-dependent optima in terms of maximizing energy for gonad growth in accordance with the model of Sebens $(1979,1982)$. Gonad size is positively correlated with body size in Metridium senile, and not a constant proportion of body weight (as for example in the other clonal species, Anthopleura elegantissima), which allows a range of habitat-dependent optimum body sizes producing an equal reproductive output of the genet (Sebens 1981b). However, the fertility of $M$. senile at a very small body size in a high-flow regime may be an adaptation of the dominant clones to habitat features allowing some sexual fecundity. Conversely, it may suggest that the small size classes $(<4 \mathrm{~g})$ in low-flow habitats have less prey available and consequently allocate more to growth and maintenance than to reproduction. Transverse sectional gonad areas of the sampled females from the Gullmarsfjord were only $1 / 10$ of those reported by Bucklin (1987) in the Californian $M$. senile fimbriatum. This comparison may to some extent be explained by different methods of analysis, but this is unlikely to explain such a large difference. Our results indicate either that the Gullmarsfjord individuals are food limited or that populations of $M$. senile in the Gullmarsfjord allocate a greater amount of energy to asexual reproduction and correspondingly a lower amount to sexual reproduction than the Californian $M$. s. fimbriatum. 
Acknowledgements. We thank Hierta-Retzius Stiftelsen and Stiftelsen Lars Hiertas Minne for providing financial support. We are grateful to Tina Olesen [Zoological Institute, Cell Biological-Anatomical Laboratory (CAL), University of Copenhagen] for assistance with histological sectioning in the laboratory, to Else Schiødt-Hansen (CAL) for important histological advice, and to Beth Beyerholm (CAL) for graphic assistance. We are grateful to staff and management of the Kristineberg Marine Research Station for providing laboratory facilities and technical assistance. Thanks are especially due to Prof. Jorgen Lützen (CAL) and Pia Rheinländer who provided valuable guidance and to Danny Eibye-Jacobsen and Tom Pearson for critical reading and linguistic corrections. Three anonymous referees improved the manuscript. This research was supported by the Swedish Natural Science Research Council, contract no. B-BU 08526-310 to I.S.

\section{LITERATURE CITED}

Begon, M., Harper, J. L., Townsend, C. R. (1986). Ecology: individuals, populations, and communities. Blackwell Scientific Publications, Oxford

Bucklin, A. (1982). The annual cycle of sexual reproduction in the sea anemone Metridium senile. Can. J. Zool. 60: 3241-3248

Bucklin, A. (1985). Biochemical genetic evidence, growth and regeneration of the sea anemone Metridium, of British shores. J. mar. biol. Ass. U.K. 65: 141-157

Bucklin, A. (1987). Adaptive advantages of patterns of growth and asexual reproduction of the sea anemone Metridium senile (L.) in intertidal and submerged populations. J. exp. mar. Biol. Ecol. 110: 225-24.3

Calow, P. (1979). The cost of reproduction - a physiological approach. Biol. Rev. 54:23-40

Chia, F. S. (1976). Sea anemone reproduction: patterns and adaptive radiations. In: Mackie, G. O. (ed.) Coelenterate ecology and behavior. Plenum, New York, p. 261-270

Fautin, D. G., Bucklin, A., Hand, C. (1989). Systematics of the sea anemones belonging to genus Metridium (Coelenterata: Actiniaria), with a description of $M$. giganteum new species. Wasmann J. Biol. 47(1-2): 77-85

Gemmill, J. F. (1920). The development of the sea anemones Metridium dianthus (Ellis) and Adamsia palliata (Bohad). Phil. Trans. R. Soc. Lond. B 209: 351-375

Giese, A. C., Pearse, J. S. (1974). Reproduction of marine invertebrates. Academic Press, New York

Grant, A., Tyler, P. A. (1983a). The analysis of data in studies of invertebrate reproduction. I. Introduction and statistical analysis of gonad indices and maturity indices. Int. J. Invert. Reprod. 6: 259-269

Grant, A., Tyler, P. A.. (1983b). The analysis of data in studies of invertebrate reproduction. II. The analysis of oocyte size/frequency data, and comparison of different types of data. Int. J. Invert. Reprod. 6: 271-283

Hammatt, M. L. (1906). Reproduction of Metridium marginatum by fragmental fission. Am. Nat. 40: 583-591

Harris, L. G. (1973). Nudibranch associations. In: Cheng, T. C. (ed.) Current topics in comparative pathobiology, Vol. 2 Academic Press, New York, p. 213-315

Harris, L. G. (1986). Size-selective predation in a sea anemone, nudibranch, and fish food chain. Veliger 29 : $38-47$

Hoffmann, R. J. (1976). Genetics and asexual reproduction of the sea anemone Metridium senile. Biol. Bull. 151. $478-488$

Hoffmann, R. J. (1986). Variation in contributions of asexual reproduction to the genetic structure of populations of the sea anemone Metridium senile. Evolution 40(2): 357-365

Hughes, R. N., Cancino, J. M. (1985). An ecological overview of cloning in metazoa. In: Jackson, J. B. C.. Buss, L. W., Cook, R. E. (eds.) Population biology and evolution of clonal organisms. Yale University Press, New Haven, p. $153-186$

Hurlbert, S. H. (1984). Pseudoreplication and the design of ecological field experiments. Ecol. Monogr. 54(2): 187-211

Koehl, M. A. R. (1977). Effects of sea anemones on the flow forces they encounter. J. exp. Biol. 69: 87-105

Koehl, M. A. R. (1982). The interaction of moving water and sessile organisms. Scient. Am. 247: 110-134

Manuel, R. L. (1988). British Anthozoa. Synopses of the British fauna No. 18 (revised). E. J. Brill, Leiden

Moe, M. A. J. (1982). The marine aquarium handbook. Green Turtle Publications, Plantation, FL

Muus, B. J. (1968). A field method for measuring 'exposure' by means of plaster balls. Sarsia 34:61-68

Pearse, J. S., Pearse, V. B., Newberry, A. T (1989). Telling sex from growth: dissolving Maynard-Smith's paradox. Bull. mar. Sci. $45(2)$ : $433-446$

Prente, P. (1979). Praktisk vejledning i histologisk-histokemisk metodik. Institut for Almen Zoologi, Copenhagen

Purcell, J. E. (1977). Aggressive function and induced development of catch tentacles in the sea anemone Metridium senile (Actiniaria: Coelenterata). Biol. Bull. 153: 355-368

Rawlinson, R. (1934). A comparative study of Metridium senile (L.) var. dianthus (Ellis) and a dwarf variety of this species occurring in the River Mersey, with a discussion on the systematic position of the genus Metridium. J. mar. biol. Ass. U.K. 19: 901-919

Sebens, K. P. (1979). The energetics of asexual reproduction and colony formation in benthic marine invertebrates. Am. Zool. 19: 683-697

Sebens, K. P. (1981a). The allometry of feeding, energetics, and body size in three sea anemone species. Biol. Bull. 161: $152-171$

Sebens, K. P. (1981b). Reproductive ecology of the intertidal sea anemones Anthopleura xanthogrammica and $A$. elegantissima: body size, habitat, and sexual reproduction. J. exp. mar. Biol. Ecol. 54: 225-250

Sebens, K. P. (1982). The limits to indeterminate growth: an optimal size model applied to passive suspension feeders. Ecology 63(1): 209-222

Shick, J. M. (1991). A functional biology of sea anemones. Chapman \& Hall, London

Shick, J. M., Hoffmann, R. J. (1980). Effects of the trophic and physical environments on asexual reproduction and body size in the sea anemone Metridium senile. In: Tardent, P., Tardent, R. (eds.) Developmental and cellular biology of coelenterates. Elsevier/North Holland, Amsterdam, p. 211-216

Shick, J. M., Hoffmann, R. J., Lamb, A. N. (1979). Asexual reproduction, population structure, and genotype-environment interactions in sea anemones. A.m. Zool. 19: $699-713$

SokaI, R. R., Rohlf, F. J. (1969). Biometry. W. H. Freemann, San Francisco

Sokal, R. R., Rohlf, F. J. (1981). Biometry, 2nd edn. W. H. Freeman \& Co, San Francisco

Stephenson, T A. (1935). The British sea anemones, Vol. II. Ray Socjety, London

Svane, I. (1988). Recruitment and development of epibioses on artificial and cleared substrata at two sites in Gullmarsfjorden on the Swedish west coast. Ophelia 29(1): 25-41 
Wahl, M. (1985). Metridium senile: dispersion and small scale colonization by the combined strategy of locomotion and asexual reproduction (laceration). Mar. Ecol. Prog. Ser. 26: $271-277$

Wainwright, S. A., Koehl, M. A. R. (1976). The nature of flow

This article was submitted to the editor and the reaction of benthic cnidaria to it. In: Mackie, G. O (ed.) Coelenterate ecology and behavior Plenum Press, New York, p. 5-21

Williams, G. C. (1975). Sex and evolution. Princeton University Press, Princeton

Manuscript first received: January 27, 1994 Revised version accepted: August 11, 1994 